\title{
The Green Climate Fund - a beacon for climate change action
}

\author{
F. Javier Manzanares
}

Correspondence: jmanzanares@gcfund.org 175 Artcenter-daero, Songdo-dong, Yeonsu-gu, Incheon, South Korea

\section{Background and purpose of GCF}

The Green Climate Fund's mission is to enhance human action to respond to climate change. The Fund aims to mobilize funding at scale to invest in low-emission and climate-resilient development.

The Fund was established by 196 sovereign governments that are Parties to the UN Framework Convention on Climate Change (UNFCCC) and is guided by the Conference of the Parties (COP) to the Convention. GCF is the only multilateral financing institution set up with the sole goal of supporting the UNFCCC's climate objectives. The Fund was initially established during the Cancun COP in 2010, and its governing instrument was adopted at the Durban COP the following year. The Board met for the first time in 2012, and a permanent Secretariat was established to support the Fund's work in 2013, headquartered in Songdo, Republic of Korea.

Last year's Paris Agreement, negotiated and approved at COP21, has provided a new role to the Green Climate Fund, designating the Fund as part of the financial mechanism to the new Agreement. This mandate reinforced the Fund's role at the heart of the international community's commitment to keep global average temperature rise below $2{ }^{\circ} \mathrm{C}$ and to strive to keep the rise below $1.5{ }^{\circ} \mathrm{C}$.

The Fund's vision is to support a paradigm shift to low emission and climateresilient development. The Fund is driven by innovation and targets its investments for transformational impact. It seeks to create new models for climate finance, channeling investment from both the public and private sectors. It aims to maximize the impact of public finance in a creative way, and to attract new sources of private finance to catalyze investment in adaptation and mitigation projects in the developing world.

\section{GCF's achievements so far}

The Fund has travelled a long way in a short time in order to start fulfilling this ambitious mandate. Since opening its doors in December 2013 it has established the principles, policies and procedures necessary to ensure both efficiency and accountability for this unique enterprise. That was necessary in order to earn the trust of the international community, and to pave the way for the Fund's capitalization.

The Fund's initial resource mobilization took place in 2014, and GCF raised over USD 10.3 billion in pledges from 35 countries, including both developed and developing states. This is a record for international climate finance mobilization, and this funding, intended

(c) The Author(s). 2017 Open Access This article is distributed under the terms of the Creative Commons Attribution 4.0 International License (http://creativecommons.org/licenses/by/4.0/), which permits unrestricted use, distribution, and reproduction in any medium, provided you give appropriate credit to the original author(s) and the source, provide a link to the Creative Commons license, and indicate if changes were made. 
to cover an initial period from 2015 to 2018 , has given GCF the means to get to work on mitigation and adaptation activities.

GCF approved its first project investments on schedule in 2015, just ahead of the Paris COP meeting. The Board has set an ambitious aspirational goal to allocate USD 2.5 billion in climate finance by the end of 2016. Following decisions taken at the Board's fourteenth meeting in October 2016, the Fund's aggregated portfolio comprises 27 projects and programmes, with a total GCF funding amount of USD 1,212 million, and USD 3,915 million in total project costs. The Fund has also recently started disbursing finance to these projects, making its first funding transfer in September 2016.

The Fund has made truly remarkable strides from conception to execution in just a few years. But much more is expected of GCF in the years to come. The following sections examine how the Fund is structured, and how it makes decisions on allocating its funds.

\section{Structure and procedures}

At the Fund's heart is a balanced governance structure that ensures consensus-based decisions between developing and developed countries. The Fund is governed by a Board of twenty-four members, equally drawn from developed and developing countries, with two Co-Chairs, one each from a developed and developing country.

Representation from developing countries includes representatives of relevant United Nations regional groupings and representatives from small island developing States and least developed countries. Each Board member has an alternate member, and Board members and their alternates are selected by their respective constituency or regional group within a constituency. They serve for a term of 3 years and are eligible to serve additional terms as determined by their constituency. There is no voting, but rather the Board reaches decisions through consensus.

One of the first tasks for the Board was to establish rigorous fiduciary principles and standards as well as environmental and social safeguards to govern all of the Fund's activities. The Board has also adopted policies which guide the Fund's financial risk management and investments. These include ensuring that in its initial stages, grants will constitute at least $50 \%$ of the total contributions to the Fund. The Fund measures its impact through an initial results management framework, which sets targets for all investments. The World Bank currently serves as the interim trustee to manage the financial assets of the Fund.

\section{Country ownership and National Designated Authorities}

The Fund's approach is strongly country-driven, engaging with countries to ensure that its investments are aligned with national priorities, promoting direct access for national entities, and providing readiness grants that build national capacity. It is this national engagement which enables the Fund to act as a facilitator for countries to implement their Intended Nationally Determined Contributions (INDCs) - the key element of the Paris Agreement.

The Fund recognises the need to ensure that developing country partners exercise ownership of climate change funding and integrate it within their own national action plans. The Governing Instrument of the Fund makes clear that it will adopt a 
country-driven approach and strengthen program coherence and stakeholder coordination at the national level. To support this in every developing country there are National Designated Authorities (NDAs) who are the interface between each country and the Fund. These focal points communicate the Country's strategic priorities for financing low-emission and climate-resilient development across its economy. Over 130 countries have selected NDAs to play this role. They are chosen by Governments to act as the core interface between a developing country and the Fund. The NDAs provide broad strategic oversight of GCF's activities in a country and serve as the point of communication with the Fund.

\section{Country readiness support}

It is crucial that developing countries are able to effectively access and deploy resources from the Fund. That is why the Fund provides early support for readiness and preparatory activities to enhance country ownership and access. This 'country readiness' funding is a dedicated and cross-cutting programme that maximises the effectiveness of the Fund by empowering developing countries. These readiness and preparatory support activities are not one-off measures, but are part of an ongoing process to strengthen a country's engagement with the Fund. The Fund focuses its readiness support on particularly vulnerable countries, including small island developing States (SIDS), least developed countries (LDCs) and African States - a minimum of 50\% of country readiness funding is targeted at supporting these countries.

\section{Getting projects done: the role of implementing entities}

The Fund relies upon a network of partner institutions known as accredited entities to deliver projects on the ground, and to date has accredited 41 organisations to partner with it. These accredited entities include national, regional and international organisations, drawn from the public, private and non-governmental sectors. Recipient countries are also allowed direct access through accredited sub-national, national and regional implementing entities they propose and set up as long as these implementing entities fulfil certain fiduciary standards.

This growing network of well-established, trusted partners works closely with the Fund to effectively and efficiently deploy funding to support the Fund's objectives. The Fund ensures this through a rigorous accreditation system. Applications are made via an online accreditation system, and are then reviewed by a Board committee on an ongoing basis before final approval from the Board.

Implementing Entities have a responsibility to develop and submit funding proposals for projects and programmes. They then oversee management and implementation of projects and programmes, deploy a range of financial instruments within their respective capacities (grants, concessional loans, equity \& guarantees), and mobilise private sector capital.

\section{Financial instruments}

The Green Climate Fund is able to use a variety of financial instruments to realise its goals, including concessional loans, subordinated debt, equity, guarantees and grants. These financial tools allow the Fund the flexibility to tailor its support to the project 
needs of public, private and nongovernmental entities. This is particularly useful for those developing countries in which climate action requires the full flexibility of financial instruments and counterpart risk-taking, beyond fiscally-constrained central governments.

The Fund is unique in its ability to engage directly with both the public and private sector in transformational climate-sensitive investments. As part of its innovative framework, the Fund has the capacity to bear significant climate related risk, allowing it to leverage and crowd-in additional financing. The Fund offers a wide range of financial products, enabling it to match project needs and adapt to specific investment contexts, including using its funding to overcome market barriers for private finance.

\section{Applying for grants}

Project proposals can come from a variety of sponsors within a country, including public, private and not-for-profit entities. Proposal sponsors work with an accredited intermediary or Implementing Entity to develop proposals. The Implementing Entity then carries out a funding proposal appraisal to assess the entire project or programme's viability, assessing a variety of considerations including climate change, environmental, social, gender, economic, and financial factors. Following the initial proposal approval process, a two-set process is followed - the first step being an analysis and recommendation from the Secretariat, then followed by a Board decision as to whether to approve the proposal.

\section{Making decisions: GCF's policies on project selection}

So with such an ambitious mandate, how does the Board decide to prioritise its investments?

In order to support the development of its project portfolio, the Board has established a number of principles and policies to guide decision-making, and to help countries and accredited entities in developing project proposals.

Some of these are specified directly within the Fund's governing instrument, as established by the UNFCCC parties, whilst the Board has also approved an initial investment framework to give further details. This investment framework plays a key role in translating the Fund's overall objectives into clear guidelines for investment decisions. Its adoption in 2014 marked a major step towards full operationalization.

One of GCF's central principles is that the Fund aims for a 50:50 balance between mitigation and adaptation investments over time. This focus on a balance between mitigation and adaptation activities is crucial, and is also aimed at re-balancing the flows of international climate finance. The poorest people, and poorest countries are likely to be most affected by the impacts of climate change, so GCF also aims for a floor of fifty percent of the adaptation allocation to be reserved for particularly vulnerable countries, including Least Developed Countries, Small Island Developing States and African states.

Beyond these general principles, the Board has developed a set of investment criteria to evaluate where the Fund can make the most effective investments. These criteria aim to targets investments to achieve paradigm shift towards low-emissions, climateresilient development. The Fund's six investment criteria are impact potential, paradigm 
shift potential, sustainable development potential, country ownership, efficiency and effectiveness, and the needs of the recipient.

Alongside these investment criteria, the Board has also identified and prioritized eight adaptation and mitigation results areas as part of its investment framework. The eight results areas cover both mitigation and adaptation, and provide the reference points to guide the Fund and its stakeholders to ensure a strategic approach when developing programmes and projects, whilst respecting the needs and priorities of individual countries.

The results areas have been targeted because of their potential to deliver a substantial impact on mitigation and adaptation. The eight results areas are energy generation and access; transport; buildings, cities, industries and appliances; land use, deforestation, forest degradation; enhanced livelihoods of vulnerable people and communities; food, water security and health; infrastructure; and ecosystems and ecosystem services.

Together, these six investment criteria and eight results areas provide the Board, countries, and accredited entities with guidance on how the Fund seeks to shape its investment decisions. Since the first project decisions were taken in December 2015, the Fund's project portfolio has started to take shape. The twenty-seven projects approved to date range from small-scale investments to strengthen the resilience of Pacific islands through to large-scale programmes to develop private sector markets in renewable energy. What is clear is the Board's determination for the Fund to achieve a real paradigm shift through its investments, whether in terms of building climate resilience, or supporting the transition to low-emission economies.

\section{Prospects for the future}

The unprecedented agreement at the Paris COP, and the rapid ratification of the Paris Agreement into force show that the international community appreciates how urgent it is to act on the climate. GCF has moved from an initial idea to a fully-fledged Fund with a developing project portfolio in just a few short years. It will clearly need to move even further, and even faster in the future if it is to deliver on its ambitious mandate to help the international community to keep average global temperature rise well below $2^{\circ}$ Celsius.

Acknowledgement

The author gratefully acknowledges the contribution of Michel Smitall, the Communication Senior Specialist of GCF, to this policy note. 